\title{
Retrosternal dislocation of the clavicle: an important injury easily missed
}

\section{J. WORRELL AND G. N. FERNANDEZ}

Department of Accident and Emergency Medicine, Queen Alexandra Hospital, Portsmouth, England

\section{INTRODUCTION}

Dislocation of the sternoclavicular joint is an uncommon injury. The anterior displacement is well recognized but posterior displacement is much more unusual, one per 1600 cases of shoulder trauma (Rowe \& Marble, 1958).

Early diagnosis is important as this affects ease of reduction and awareness of possible damage to the great vessels in the mediastinum.

We report two cases where the diagnosis was missed.

\section{CASE 1}

A 50-year-old man injured his right shoulder when his car slid off the road on a patch of ice. He was seen at the local accident and emergency department and discharged with his arm in a sling, his $\mathrm{X}$-rays being reported as normal.

He presented to our department, via his general practitioner, the following day with severe pain in the base of his neck on the right. Examination showed his head to be tilted to the right, there was loss of contour and swelling over the medial end of the right clavicle, with $4 \mathrm{~cm}$ of shortening. X-ray confirmed posterior dislocation of the right sternoclavicular joint (Fig. 1).

The dislocation was reduced under general anaesthesia, using backward pressure on the shoulder tips over a sandbag between the scapulae. This reduction was stable and relieved his neck pain totally. At follow-up 3 weeks later he had a near-normal range of shoulder movement. 


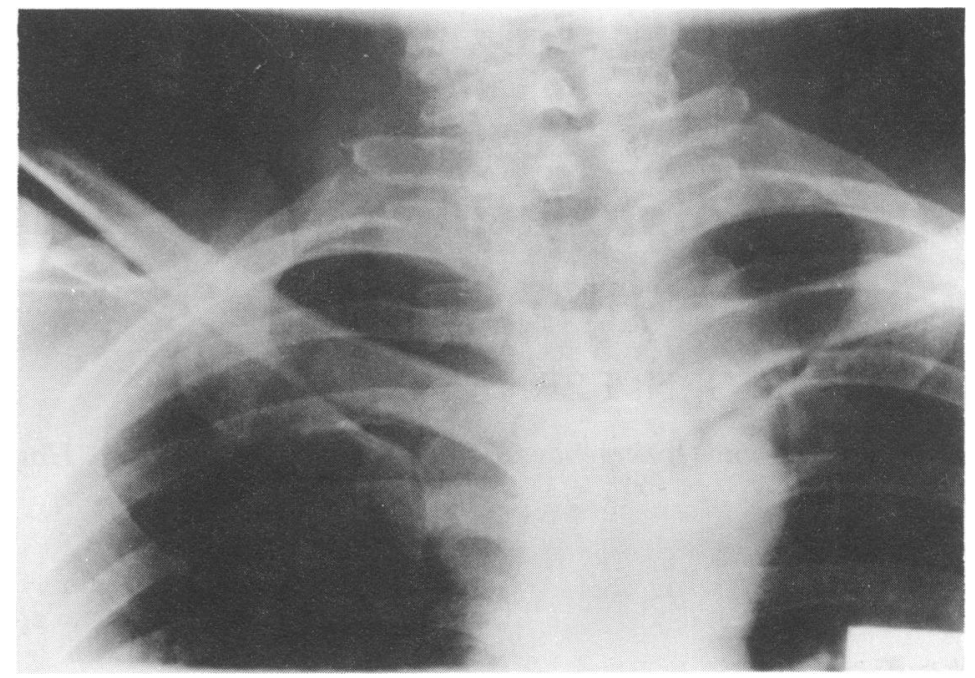

Fig. 1 Views of sternoclavicular joint showing disclocation on the right side.

\section{CASE 2}

A 15-year-old girl who fell whilst playing netball presented with a painful rig shoulder. She was examined and X-rayed by the junior staff who could find no abnormality (Fig. 2). Because of her complaint of severe pain at the base of the neck, advice was asked of senior accident staff and the diagnosis of retrosternal dislocation was then made.

The dislocation was reduced successfully under general anaesthetic and was stable. Her movements were initially quite restricted and recovered slowly over a period of 6 ? weeks.

\section{DISCUSSION}

These two cases show how easily this injury may be missed. The clinical clue is the pain in the base of the neck, which appears out of all proportion to a 'normal'-looking shoulder, and is worsened by shoulder movement. Early diagnosis is essential if closed reduction is to succeed. Open reduction is usually required after 48 hours (Selesnick et al., 1984).

The great vessels in the superior mediastinum may be damaged by this injury (Gardner \& Bidstrup, 1983) and urgent surgical intervention may be needed. The relation of the medial end of the clavicle to these structures is best visualized by C.T. scanning (Selesnick et al., 1984).

Accident and emergency department staff need to be aware of this unusual and $\frac{0}{0}$ possibly serious injury. 


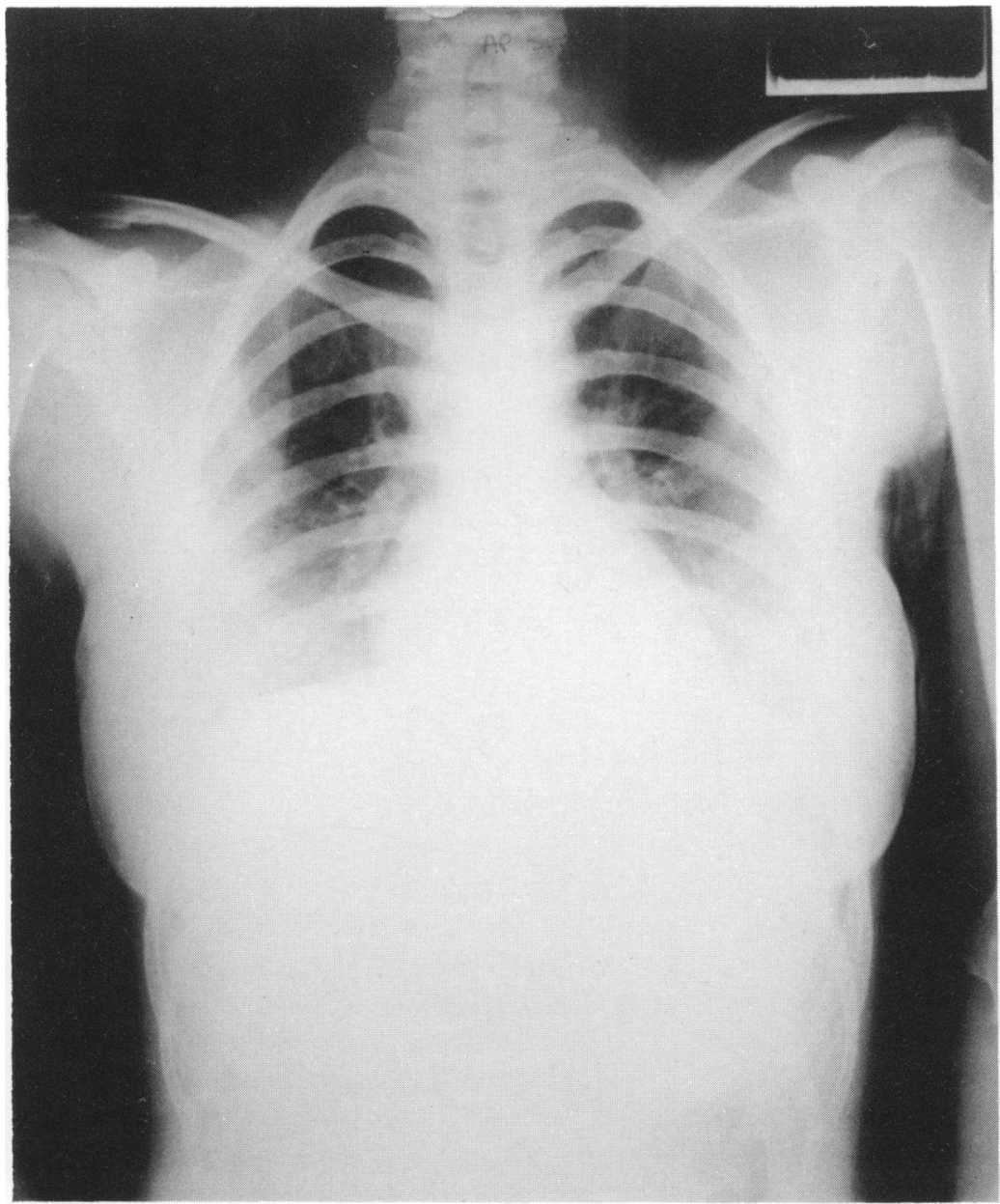

Fig. 2 X-ray showing asymmetry of clavicle due to right-sided dislocation.

\section{REFERENCES}

Gardner M. A. H. \& Bistrup B. P. (1983) Intrathoracic great vessel injury resulting from blunt chest trauma associated with posterior disclocation of the sternoclavicular joint. Australia and New Zealand fournal of Surgery 53, 427-30.

Rowe C. R. \& Marble H. C. (1958) Sternoclavicular dislocations. In Fractures and other Injuries, E. F. Cave (ed.). P. 258. Chicago, Year Book Medical.

Selesnick F. H., Jablon M., Frank C. \& Post M. (1984) Retrosternal dislocation of the clavicle. fournal of Bone and foint Surgery 66-A, 287-91.

Received 23 fuly 1985; accepted 28 October 1985 